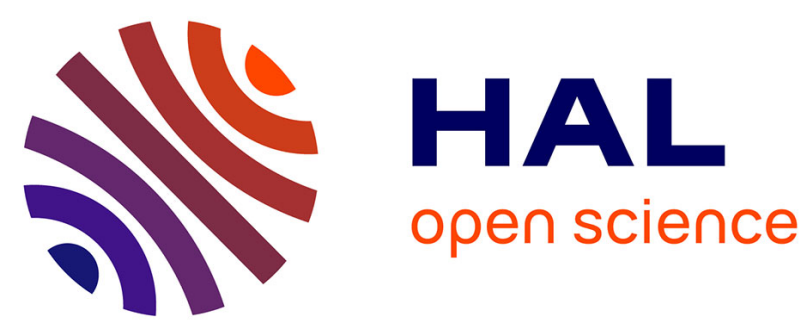

\title{
Increased risk of acute arterial events in young patients and severely active IBD: a nationwide French cohort study.
}

Julien Kirchgesner, Laurent Beaugerie, Fabrice Carrat, Nynne Nyboe Andersen, Tine Jess, Michaël Schwarzinger

\section{To cite this version:}

Julien Kirchgesner, Laurent Beaugerie, Fabrice Carrat, Nynne Nyboe Andersen, Tine Jess, et al.. Increased risk of acute arterial events in young patients and severely active IBD: a nationwide French cohort study.. Gut, 2018, 67 (7), pp.1261-1268. 10.1136/gutjnl-2017-314015 . hal-02878393

\section{HAL Id: hal-02878393 \\ https://hal.sorbonne-universite.fr/hal-02878393}

Submitted on 23 Jun 2020

HAL is a multi-disciplinary open access archive for the deposit and dissemination of scientific research documents, whether they are published or not. The documents may come from teaching and research institutions in France or abroad, or from public or private research centers.
L'archive ouverte pluridisciplinaire HAL, est destinée au dépôt et à la diffusion de documents scientifiques de niveau recherche, publiés ou non, émanant des établissements d'enseignement et de recherche français ou étrangers, des laboratoires publics ou privés. 
Increased risk of acute arterial events in young patients and severely active inflammatory bowel disease: a nationwide French cohort study

Julien Kirchgesner (1,2), Laurent Beaugerie $(1,3)$, Fabrice Carrat $(2,4)$, Nynne Nyboe Andersen (5,6), Tine Jess $(5,7)$, Michaël Schwarzinger $(8,9)$, for the BERENICE study $\operatorname{group}^{A}$

Short title: Acute arterial events and inflammatory bowel disease

(1) Department of Gastroenterology, AP-HP, Hôpital Saint-Antoine, Paris, France

(2) UMRS 1136, INSERM, UPMC Univ Paris 06, Sorbonne Universités, Paris, France

(3) ERL 1057 INSERM/UMRS 7203 and GRC-UPMC 03, UPMC Univ Paris 06, Paris, France

(4) Department of Public Health, AP-HP, Hôpital Saint-Antoine, Paris, France

(5) Department of Epidemiology Research, Statens Serum Institute, Copenhagen, Denmark

(6) Department of Gastroenterology, Zealand University Hospital, Køge, Denmark

(7) Department of Clinical Epidemiology, Bispebjerg Hospital, Copenhagen, Denmark

(8) THEN, Translational Health Economics Network, Paris, France

(9) Infection Antimicrobials Modeling \& Evolution (IAME), UMR 1137, INSERM, Université Paris Diderot, Sorbonne Paris Cité, Paris, France.

A Collaborators of the BERENICE Study Group are listed at the end of the manuscript

Corresponding author: Julien Kirchgesner, Service de Gastroentérologie et Nutrition, Hôpital Saint-Antoine, 184 rue du faubourg Saint-Antoine, 75571 Paris CEDEX 12, France. Tel: +33 $149428 \quad 31$ 72, Fax: $+33 \quad 1 \quad 4928$ 31 88 . E-mail: julien.kirchgesner@gmx.com 
Author Contributions:

Julien Kirchgesner: study concept and design; acquisition of data; analysis and interpretation of data; drafting of the manuscript; critical revision of the manuscript for important intellectual content; statistical analysis.

Laurent Beaugerie: study concept and design; analysis and interpretation of data; drafting of the manuscript; critical revision of the manuscript for important intellectual content.

Fabrice Carrat: analysis and interpretation of data; critical revision of the manuscript for important intellectual content.

Nynne Nyboe Andersen: analysis and interpretation of data; critical revision of the manuscript for important intellectual content.

Tine Jess: study concept and design; analysis and interpretation of data; critical revision of the manuscript for important intellectual content.

Michael Schwarzinger: study concept and design; acquisition of data; analysis and interpretation of data; drafting of the manuscript; critical revision of the manuscript for important intellectual content; study supervision.

Body text word count: 3984 words, excluding title page, abstract, references, figures and tables.

Abstract word count: 248 words. 


\section{Abstract}

Objective: Magnitude and independent drivers of the risk of acute arterial events in inflammatory bowel disease (IBD) are still unclear. We addressed this question in patients with IBD compared to the general population at a nationwide level.

Design: Using the French National Hospital Discharge Database from 2008 to 2013, all patients aged 15 years or older and diagnosed with IBD were identified and followed up until 31 December 2013. The rates of incident acute arterial events were calculated and the impact of time with active disease (period around hospitalisation for IBD flare or IBD-related surgery) on the risk was assessed by Cox regression adjusted for traditional cardiovascular risk factors.

Results: Among 210,162 individuals with IBD (Crohn's disease [CD], $n=97,708$; ulcerative colitis [UC], $n=112,454), 5,554$ incident acute arterial events were identified. Both patients with $C D$ and $U C$ had a statistically significant overall increased risk of acute arterial events (standardised incidence ratio [SIR] 1.35; 95\% confidence interval [95\% Cl] 1.30-1.41 and SIR, 1.10; 95\% Cl, 1.06-1.13, respectively). The highest risk was observed in patients under the age of 55 years, both in CD and UC. The 3-month periods before and after IBD-related hospitalisation were associated with an increased risk of acute arterial events in both $\mathrm{CD}$ and $\mathrm{UC}$ (hazard ratio, 1.74; $95 \% \mathrm{Cl}, 1.44-2.09$ and $1.87 ; 95 \% \mathrm{Cl}, 1.58-2.22$, respectively).

Conclusion: Patients with IBD are at increased risk of acute arterial events, with the highest risk in young patients. Disease activity may also have an independent impact on the risk. 
Keywords: Inflammatory bowel disease, cardiovascular disease, ischemic heart disease, cerebrovascular disease, peripheral arterial disease.

Abbreviations used in this paper: IBD: Inflammatory bowel disease; CD: Crohn's disease; UC: Ulcerative colitis; PMSI: Programme de Médicalisation des Systèmes d'Information; ICD-10: WHO International Classification of Diseases, 10th revision; SIR: standardised incidence ratio. 


\section{Summary box}

What is already known about this subject?

- Chronic systemic inflammation is associated with an increased risk of acute arterial events.

- $\quad$ Risk of acute arterial events in IBD remains debated, while risk differences between age categories and the impact of disease activity remain largely unexplored and may explain contradicting previous findings.

What are the new findings?

- $\quad$ Patients with IBD are at increased risk of acute arterial events, with the highest risk in younger patients for all arterial disease groups.

- $\quad$ Disease activity may be an independent risk factor of acute arterial events.

How might it impact on clinical practice in the foreseeable future?

- $\quad$ Our nationwide population-based cohort study suggests an increased risk of ischemic heart disease, cerebrovascular disease and peripheral artery disease in patients with IBD, notably in younger patients and those with severely active disease. Strategies for optimizing control of inflammation should be assessed, in order to decrease the risk of acute arterial events in this patient population. 


\section{INTRODUCTION}

Inflammatory bowel diseases (IBD), including Crohn's disease (CD) and ulcerative colitis (UC), are characterised by chronic intestinal and systemic inflammation. Chronic systemic inflammation is involved in the pathogenesis of atherosclerosis and associated with increased risk of acute arterial events.[1,2] However, the risk of acute arterial events in patients with IBD remains unclear, in contrast with other chronic inflammatory disorders such as rheumatoid arthritis and systemic lupus erythematosus.[3-5] In one meta-analysis,[6] IBD was significantly associated with increased risks of ischemic heart disease and cerebrovascular disease, but no significant association was found for peripheral artery disease. In another metaanalysis,[7] no increased risk of acute arterial events was found in patients with IBD.[6] Thus the data are inconsistent and further generalisation of results is limited by the considerable heterogeneity found between studies.[6]

Several factors may explain the conflicting data on the association between IBD and acute arterial events, notably age and disease activity. Several studies reported an association between younger age and an increased risk of acute arterial events,[8-10] while an increased risk of myocardial infarction was reported specifically in patients of older age.[11] Regarding disease activity, only one study reported the association between disease activity and the risk of myocardial infarction and stroke, but did not include peripheral artery disease.[12] Hence, the magnitude of the risk and the independent risk factors of acute arterial events in patients with IBD remain unclear and need further investigation.

Our aim was to assess the risk of acute arterial events, including ischemic heart disease, cerebrovascular disease, and peripheral artery disease in patients with IBD 
as compared to the general population, and to assess the impact of age and IBD activity on the risk of acute arterial events, at a nationwide level. 


\section{MATERIALS AND METHODS}

\section{Data source}

The French National Hospital Discharge Database (Programme de Médicalisation des Systèmes d'Information [PMSI]) covers all public and private hospitals in France. The standardised discharge summary includes: patient's demographics; primary and associated discharge diagnosis codes (WHO International Classification of Diseases, 10th revision, ICD-10);[13] medical and surgical procedures performed (French Medical Common Procedure Coding System); length of stay, entry and in-hospital mortality, which accounted for $57.4 \%$ of all adult deaths recorded in France between 2008 and 2013.[14] A unique anonymous identifier allows linking all hospital claims of the patient since January 2008 and tracking the occurrence and progression of chronic conditions over time.

\section{Study population}

All patients, aged 15 years or older, identified with IBD between 2008 and 2013 from the PMSI were included. Identification of IBD cases was based on one hospitalisation discharge diagnosis both as primary or associated diagnosis related to CD (K50) or UC (K51). The ICD-10 code for indeterminate colitis (K52.3) was not considered in this study. Detailed individual-level information regarding hospitalisations was available from 1 January 2008. Date of cohort inclusion was 1 January 2010 for patients diagnosed with IBD before 1 January 2010 and the date of first hospital claim related to IBD for patients identified after 1 January 2010. In case of multiple hospitalisations related to both $U C$ and $C D$, the most recent diagnosis at cohort inclusion was retained. All subjects were followed until occurrence of any outcome, in-hospital death, or end of the study, 31 December 2013, whichever came first. 
The general population at risk consisted in all adults ( 15 years or older) residing in France (National Vital Statistics in January of each year of the study period), hence including IBD and non-IBD individuals. Incident acute arterial events among non-IBD individuals were assessed from the PMSI between 1 January 2008 and 31 December 2013. Individuals diagnosed with IBD after 1 January 2010 contributed person-time as non-IBD individuals until the date of IBD diagnosis.

The same exclusion criteria were applied in the IBD population and the general population and were identified between 1 January 2008 and date of cohort inclusion (i.e. at least during 2 years of follow-up for every patient). Individuals with a history of an acute arterial event or related cardiovascular disease, primary or associated discharge diagnosis of atrial fibrillation, heart failure, or cardiomyopathy, procedures related to cardiac electronic device, cardiac valve prosthesis, angiography, coronary catheterization, or coronary artery bypass grafting were excluded (Supplementary Table 1).

\section{Outcomes}

Study outcome was the first occurring acute arterial event following cohort entry, defined by a primary discharge diagnosis or procedures specifically related to: (1) ischemic heart disease (including myocardial infraction); (2) cerebrovascular disease (including stroke); (3) peripheral artery disease, excluding acute mesenteric ischemia. We did not include acute mesenteric ischemia, since local intestinal rather than systemic inflammation may be associated with acute mesenteric ischemia in patients with IBD. $[15,16]$ See Supplementary Table 1 for the according ICD-10 codes and procedure codes. 


\section{Covariates}

Traditional cardiovascular risk factors including hypertension, hyperlipidemia, diabetes mellitus, obesity, tobacco smoking, and alcohol use disorders were assessed during each hospitalisation between 1 January 2008 and end of follow-up (Supplementary Table 2). Since assessment during hospitalisation may underestimate the prevalence of cardiovascular risk factors, which additionally may be undiagnosed although already present until the occurrence of an acute arterial event, cardiovascular risk factors were considered present at cohort entry in the main analysis if recorded at any time during follow-up. Disease activity prior to cohort entry for patients diagnosed with IBD before 1 January 2010 or at cohort entry for patients identified after 1 January 2010 was assessed by three mutually exclusive categories: (1) hospitalisation not related to IBD with an associated diagnosis of IBD (without day hospitalisation for IBD related endoscopy or hospitalisation related to IBD activity or surgery); (2) day hospitalisation for IBD related endoscopy (without hospitalisation related to IBD activity or surgery; (3) hospitalisation related to IBD activity or surgery.

\section{Statistical analysis}

Continuous data are expressed as median (interquartile range), while discrete data are given as percentages, and comparisons were made with Pearson's $\mathrm{x} 2$ test.

The incidence rate of acute arterial events was assessed for patients with IBD and for the French general population, between 2010 and 2013. The expected number of cases of acute arterial events in the general population was obtained by multiplying person-years at risk in each 5-year age group by the corresponding sex-, age- and region-specific incidence rate for each year between 2010 and 2013. The reported number of cases of acute arterial events was divided by the expected number to obtain standardised incidence ratios (SIRs). Confidence intervals (Cls) were calculated with 
an exact method based on the Poisson distribution. Lastly, subgroups analyses were performed by age groups $(15-34 ; 35-54 ; 55-74 ; 75$ years or older $)$, sex, and number of traditional cardiovascular risk factors in patients with IBD (compared to the general population and irrespective of the number of cardiovascular risk factors in the general population).

In order to assess the impact of disease activity on the risk of acute arterial events among patients with IBD, hospitalisations or surgery related to IBD were used as surrogate markers for disease activity. Active disease was defined as the three months before and after an IBD-related hospitalisation or surgery. In case of readmission related to IBD in the three months following an IBD-related hospitalisation, period of disease activity was extended to coincide with the date of the readmission. The three months after cohort inclusion were likewise defined as a period of IBD activity in patients hospitalised for IBD activity at cohort entry. A Cox regression analysis was performed separately for each IBD subtype and adjusted for age at cohort entry, sex, region of residence, year of cohort entry, disease activity prior to cohort entry, and traditional cardiovascular risk factors (hypertension, hyperlipidemia, diabetes mellitus, obesity, tobacco smoking, and alcohol use disorders). IBD activity was fitted as timevarying covariate, and periods of disease activity were compared with periods of no disease activity. All other covariates were included as time-fixed covariates. Results were reported as hazard ratios (HRs) with 95\% confidence intervals $(95 \% \mathrm{Cl})$. The proportionality of hazards was evaluated using plots of Schoenfeld residuals and no violation of the proportional hazard assumption was detected.

Since data on out-of-hospital deaths, which may mostly affect elderly people, are not available in the database, subgroups analyses were stratified on age groups (patients aged 18-54 and 55 years or older) in order to assess the impact of these lacking mortality data. Additionally, we performed several sensitivity analyses to test the 
robustness of our results. We varied the length of time patients were regarded as having active disease, reducing it to one month and extending it to six months before and after an IBD-related hospitalisation or surgery. Since cardiovascular risk factors were considered present in the main analysis if recorded at any time during follow-up, we only considered cardiovascular risk factors present at cohort entry in a sensitivity analysis. Furthermore, data on hospitalisations was available until 31 December 2013 and acute arterial events occurring between October and December 2013 may thus not be associated with IBD-related hospitalisations occurring in 2014 in our study. A sensitivity analysis was therefore performed by censoring follow-up to 30 September 2013. Lastly, we performed a sensitivity analysis excluding the postoperative period, since non-cardiac surgery is associated with a postoperative morbidity related to cardiac complications.[17]

Patients with a concomitant date of first IBD claim in the database and occurrence of acute arterial event were excluded from this analysis.

The study was approved by the French Data Protection Agency (CNIL DE-2015-025). All data used in this study only contained anonymous patient records. The statistical analyses were performed with SAS (version 9.4) statistical software (SAS Institute, Cary, NC, USA). 


\section{RESULTS}

Overall, 210,162 patients identified with IBD in the 2008-2013 French National Hospital Discharge Database were included (Figure 1): 97,708 with CD (46.5\%) and 112,454 with UC (53.5\%). The median follow-up was 3.4 years (interquartile range [IQR]:1.84.0). Patients' characteristics are shown in Table 1.

The majority of patients with IBD were women $(53.8 \%)$, with significantly higher proportions in patients with CD $(57.7 \%)$ as compared to UC $(50.5 \%) \quad(p<0.0001)$. Patients with CD were younger than patients with UC at cohort entry (median age at cohort entry [IQR]: 40 years [28 - 53] and 49 years [36 - 62], respectively). The proportion of patients with active disease prior to cohort entry was higher in patients with CD (25.9\%) compared to patients with UC (14.6\%). The majority of patients (66.3\%) were identified at cohort entry by IBD-related endoscopy. At least one cardiovascular factor was recorded in $24.8 \%$ of patients with IBD, with higher rates of tobacco smokers recorded among patients with CD $(9.6 \%)$ than patients with UC $(4.4 \%)(p<0.0001)$. A total of 5232 of patients $(2.5 \%)$ died in hospital during follow-up. 
Table 1. IBD Patient characteristics

\begin{tabular}{|c|c|c|c|}
\hline & $\begin{array}{c}\text { Crohn's } \\
\text { disease } \\
n=97,708\end{array}$ & $\begin{array}{c}\text { Ulcerative } \\
\text { colitis } \\
\mathrm{n}=112,454\end{array}$ & $\begin{array}{c}\text { Total } \\
N=210,162\end{array}$ \\
\hline Male sex & $41,369(42.3)$ & $55,636(49.5)$ & $97,005(46.2)$ \\
\hline Age at cohort entry (years) & $40(28-53)$ & $49(36-62)$ & $45(32-59)$ \\
\hline Follow-up (years) & $3.7(1.9-4.0)$ & $3.2(1.6-4.0)$ & $3.4(1.8-4.0)$ \\
\hline \multicolumn{4}{|l|}{ Disease activity prior to cohort entry } \\
\hline $\begin{array}{l}\text { Hospitalisation not related to } \\
\text { IBD activity }\end{array}$ & $17,695(18.1)$ & $11,532(10.2)$ & 29,227 (13.9) \\
\hline $\begin{array}{l}\text { Day hospitalisation } \\
\text { for IBD related endoscopy }\end{array}$ & $54,746(56.0)$ & $84,532(75.2)$ & $139,278(66.3)$ \\
\hline $\begin{array}{l}\text { Hospitalisation related to IBD activity or } \\
\text { surgery }\end{array}$ & $25,267(25.9)$ & $16,390(14.6)$ & $41,657(19.8)$ \\
\hline \multicolumn{4}{|l|}{ Cardiovascular risk factors recorded } \\
\hline Hypertension & $10,477(10.7)$ & $16,906(15.0)$ & $27,383(13.0)$ \\
\hline Hyperlipidemia & $3512(3.6)$ & $6757(6.0)$ & $10,269(4.9)$ \\
\hline Diabetes mellitus & $3706(3.8)$ & $6205(5.5)$ & $9911(4.7)$ \\
\hline Obesity & $5210(5.3)$ & $6464(5.7)$ & $11,674(5.6)$ \\
\hline Tobacco smoking & $9349(9.6)$ & $4900(4.4)$ & $14,249(6.8)$ \\
\hline Alcohol use disorders & $2383(2.4)$ & $2469(2.2)$ & $4852(2.3)$ \\
\hline
\end{tabular}




\section{Risk of any acute arterial event}

A total of 5554 acute arterial events occurred in IBD patients during 595,202 personyears of follow-up, including 3177 (57.2\%) ischemic heart diseases, 1715 (30.9\%) cerebrovascular diseases, and $662(11.9 \%)$ peripheral artery diseases. Crude incidence rates per 1000 person-years were: 9.3 (95\% Cl 9.1-9.6) for all acute arterial event; $5.3(95 \% \mathrm{Cl} 5.1-5.5)$ for ischemic heart disease; $2.9(95 \% \mathrm{Cl} 2.7-3)$ for cerebrovascular disease; and $1.1(95 \% \mathrm{Cl} 1-1.2)$ for peripheral artery disease. Crude incidence rates according to IBD subtype are provided in Supplementary Figure 1.

During the study period, $1,555,959$ French adults of the general population were hospitalised for an incident acute arterial event with a similar distribution of acute arterial events at first hospitalisation compared to patients with IBD (Supplementary Table 3). Crude incidence rates are provided by age groups for IBD patients and the general population in Supplementary Figure 2.

The risk of acute arterial events was significantly increased in patients with IBD compared to the general population (SIR, 1.19; $95 \% \mathrm{Cl} 1.16-1.22)$ (Table 2). Similar findings were found for ischemic heart disease (SIR, 1.17; $95 \% \mathrm{Cl} 1.13-1.21)$; cerebrovascular disease (SIR, 1.19; $95 \% \mathrm{Cl} 1.13-1.24)$; and peripheral artery disease (SIR, 1.27; 95\% Cl 1.17-1.37).

The risk of acute arterial events was higher in patients with $C D$ as compared to patients with UC (SIR 1.35; 95\% Cl 1.30-1.41 versus 1.10; $95 \% \mathrm{Cl} 1.06-1.13$, respectively). The risk estimates were statistically significant for all arterial disease groups, except for peripheral artery disease in patients with UC (SIR 1.07; 95\% Cl 0.96-1.18). In patients with $C D$, the highest risk was observed for peripheral artery disease (SIR 1.65; $95 \% \mathrm{Cl} 1.46-1.83)$, while the risks of ischemic heart disease and cerebrovascular disease were comparable. In UC patients, risk of ischemic heart disease and 
cerebrovascular disease were also comparable (Table 2). SIRs for arterial disease subgroups according to IBD subtype are provided in Supplementary Table 4. 
Table 2. Standardised incidence ratios of acute arterial events according to IBD subtype

Person-years $\begin{gathered}\text { Reported Expected } \\ \text { cases cases }\end{gathered}$ SIR $(95 \% \mathrm{CI}) \quad$ P value

All IBD patients

All acute arterial events Ischemic heart disease Cerebrovascular disease Peripheral artery disease

Crohn's disease patients

All acute arterial events Ischemic heart disease Cerebrovascular disease Peripheral artery disease

Ulcerative colitis patients

All acute arterial events Ischemic heart disease Cerebrovascular disease Peripheral artery disease
595,202

$\begin{array}{cccc}5554 & 4679 & 1.19(1.16-1.22) & <.0001 \\ 3177 & 2706 & 1.17(1.13-1.21) & <.0001 \\ 1715 & 1446 & 1.19(1.13-1.24) & <.0001 \\ 662 & 521 & 1.27(1.17-1.37) & <.0001\end{array}$

287,134

$\begin{array}{cccc}2244 & 1658 & 1.35(1.30-1.41) & <.0001 \\ 1253 & 956 & 1.31(1.24-1.38) & <.0001 \\ 694 & 523 & 1.33(1.23-1.43) & <.0001 \\ 297 & 180 & 1.65(1.46-1.83) & <.0001\end{array}$

308,068

$\begin{array}{cccc}3310 & 3021 & 1.10(1.06-1.13) & <.0001 \\ 1924 & 1750 & 1.10(1.05-1.15) & <.0001 \\ 1021 & 923 & 1.11(1.04-1.17) & <0.01 \\ 365 & 341 & 1.07(0.96-1.18) & 0.21\end{array}$




\section{Subgroup analyses according to age, sex and cardiovascular risk}

\section{factors}

SIRs of acute arterial events are provided by age groups and IBD subtype in Figure 2 and Supplementary Table 5. In CD patients, the highest risk was observed in patients aged from 15 to 34 years (SIR, 1.42;95\% $\mathrm{Cl} 1.09-1.75)$ and patients aged from 35 to 54 years $(\mathrm{SIR}, 1.58 ; 95 \% \mathrm{Cl} 1.45-1.70)$. The risk decreased for later age, while remaining statistically significant (SIR of patients aged from 55 to 74 years and aged of more than 75 years, $1.38 ; 95 \% \mathrm{Cl} 1.30-1.47$ and $1.13 ; 95 \% \mathrm{Cl} 1.03-1.22$, respectively). In UC patients, the highest risk was observed in patients aged from 15 to 34 years (SIR, $1.65 ; 95 \% \mathrm{Cl} 1.20-2.10)$. Conversely, the risk of acute arterial events was not increased in patients aged from 35 to 54 years (SIR, 1.02; 95\% $\mathrm{Cl} 0.93-1.11$ ) nor in patients older than 75 years (SIR, 1.05; 95\% Cl 0.99-1.11), whereas patients aged from 55 to 74 years were at increased risk (SIR, 1.15; 95\% Cl 1.09-1.20).

Compared to the general population, women with IBD were at higher risk than men with IBD for all arterial disease groups in both $C D$ and $U C$, with the highest risk in women with CD (Supplementary Figure 3). Among patients without any identified cardiovascular risk factors, an increased risk of acute arterial events was maintained in $\mathrm{CD}$ patients (SIR, 1.26; 95\% $\mathrm{Cl} 1.19-1.34$ ), whereas no increased risk was observed in UC patients (SIR, $0.96 ; 95 \% \mathrm{Cl} 0.92-1.01$ ). The risk increased progressively with an increasing number of cardiovascular risk factors (Supplementary Figure 4).

\section{Impact of IBD activity on the risk of acute arterial events}

Among 97,348 CD and 112,181 UC patients included in this analysis, 22,700 CD patients (23.3\%) and 15,747 UC patients (14\%) were hospitalised for IBD activity during follow-up. Median (IQR) duration of active disease period in $C D$ and $U C$ patients was 180 (90-205) and 92 (90-180) days, accounting for $4 \%$ and $2.1 \%$ of total follow- 
up, respectively. Among patients hospitalised for IBD activity, period of active disease accounted for $24.8 \%$ of total follow-up, while 7857 CD patients (34.6\%) and 3967 UC patients $(24.7 \%)$ were hospitalised more than once. Surgical procedures for IBD were performed in $24.9 \%$ of hospitalisations.

In CD patients, disease activity was associated with an increased risk of acute arterial events (HR, $1.74 ; 95 \% \mathrm{Cl} 1.44-2.09)$. This increased risk remained statistically significant for all arterial disease groups and the magnitude of risk was highest for peripheral artery disease (Figure 3). In UC patients, disease activity was also associated with an increased risk of acute arterial events (HR, 1.87; 95\% $\mathrm{Cl} 1.58-2.22)$, however the risk of cerebrovascular disease was not statistically significant. (Figure 3)

Regarding other predictive factors, male sex and all traditional cardiovascular risk factors except obesity were, as expected, associated with an increased risk of acute arterial events (Table 3).

Sensitivity analyses confirmed the robustness of the main results (Supplementary Table 6). Results were consistent across age groups. When the definition of duration of active disease was reduced to one month before and after an IBD-related hospitalisation, the HR for acute arterial event at the time of active disease increased in both $\mathrm{CD}$ and UC patients, to $1.91(95 \% \mathrm{Cl} 1.48-2.48)$ and $2.03(95 \% \mathrm{Cl} 1.59-2.59)$, respectively. When the definition of the duration of active disease was increased to six months before and after an IBD-related hospitalisation, the HR for acute arterial event at the time of active disease was reduced in CD and UC patients, to $1.46(95 \% \mathrm{Cl} 1.25$ $1.71)$ and 1.69 (95\% Cl 1.46-1.95), respectively. Similar results were observed in the sensitivity analyses considering only cardiovascular risk factors present at cohort entry, censoring follow-up to 30 September 2013 and excluding the postoperative period from the active disease definition. 
Table 3. Predictive factors of acute arterial events according to IBD subtype: Cox multivariate analysis*

$$
\operatorname{HR}(95 \% \mathrm{Cl})
$$

\begin{tabular}{|c|c|c|}
\hline & Crohn's disease & Ulcerative colitis \\
\hline Male sex & $1.71(1.56-1.87)$ & $2.08(1.93-2.24)$ \\
\hline $\begin{array}{l}\text { Disease activity (3-month periods before and } \\
\text { after IBD-related hospitalisation or surgery) }\end{array}$ & $1.74(1.44-2.09)$ & $1.87(1.58-2.22)$ \\
\hline \multicolumn{3}{|l|}{ Cardiovascular risk factors } \\
\hline Hypertension & $1.18(1.05-1.32)$ & $1.24(1.14-1.35)$ \\
\hline Hyperlipidemia & $1.34(1.16-1.56)$ & $1.16(1.05-1.30)$ \\
\hline Diabetes mellitus & $1.32(1.14-1.52)$ & $1.48(1.33-1.64)$ \\
\hline Obesity & $1.02(0.86-1.20)$ & $1.01(0.89-1.15)$ \\
\hline Tobacco smoking & $1.82(1.58-2.09)$ & $1.49(1.28-1.74)$ \\
\hline Alcohol use disorders & $1.52(1.26-1.84)$ & $1.51(1.27-1.79)$ \\
\hline
\end{tabular}

Abbreviation: HR, hazard ratio. * Adjusted for age at cohort entry, sex, region of residence, year of cohort entry, disease activity prior to cohort entry, hypertension, hyperlipidemia, diabetes mellitus, obesity, tobacco smoking and alcohol use disorders. 


\section{DISCUSSION}

Our study demonstrated that the overall risk of acute arterial events is increased in patients with IBD compared to the general population. The risk was higher in CD patients compared to UC patients. In CD patients, the increased risk was more prominent for younger patients with the highest risk in those aged from 35 to 54 years. For older patients, the SIRs appeared lower but the risk still remained increased compared to the general population. In UC patients, the risk was increased in patients younger than 35 years and in those aged from 55 to 74 years. Similarly to the observation in CD patients, the highest risk was observed in younger patients. Lastly, we demonstrated that the disease activity was independently associated with an increased risk of acute arterial events in both CD and UC.

With this study we have provided new evidence on the association between acute arterial events and inflammatory bowel diseases. The magnitude of the risk observed in our study for ischemic heart disease and cerebrovascular disease was similar to previous findings published in a recent meta-analysis.[6] Conversely, to the data published in the latter meta-analysis, we revealed an increased risk of peripheral artery disease in IBD patients. However, the meta-analysis only included 148 patients with peripheral artery disease, thus power limitations might explain the different findings. Moreover, systemic inflammation may be higher in peripheral artery disease than in coronary artery disease,[18] suggesting that the impact of inflammation may be higher in peripheral artery disease.

Several pathophysiological mechanisms, including structural and functional vascular changes, as well as biochemical and genetic changes may be involved in the risk of acute arterial events in patients with IBD.[19] Besides an increased carotid intimamedia thickness and arterial stiffness,[20,21] microvascular endothelial dysfunction 
was observed in patients with IBD.[22] These pathophysiological mechanisms may also support the hypothesis of a more pronounced increased risk of overall acute arterial events in CD as compared to UC patients. CD patients are more prone to a higher degree of systemic inflammation compared to UC patients, amongst others evidenced by higher level of C-reactive protein (CRP) production[23-25] and serum concentration of interleukin-6.[26] Interestingly, these markers of inflammation are increased in both IBD and atherosclerosis.[16] The difference in risk estimates between CD and UC patients could also be linked to the prothrombotic effect of hyperhomocysteinemia and low vitamin B6 plasma level, which may be related to malabsorption in CD patients.[27,28] Lastly, polymorphisms in NOD2/CARD15 have been associated with both coronary atherosclerosis and IBD with a stronger link with CD.[29] NOD2/CARD15 variants may predispose to CD.[30]

Higher risk of acute arterial events observed in younger IBD patients may reflect the different impact of inflammation across age groups. Indeed, patients diagnosed with $\mathrm{CD}$ at young age are more likely to have a severe disease course[31] and age ranges associated with an increased risk in patients with UC correspond to peak ages for UC onset.[32,33] Moreover, disease activity tends to decrease over time.[34] Traditional cardiovascular risk factors in older patients may also potentially outweigh the risk related to systemic inflammation owing to IBD.

Compared to the general population of similar sex and age, women were at higher risk of acute arterial events than men, whereas male sex was, as would be expected, an independent predictive factor of acute arterial event in IBD patients after adjustment of all cardiovascular risk factors. It suggests that the risk differences compared to the general population between men and women may be related to the higher prevalence of traditional cardiovascular risk factors in men compared with women. 
This study has several strengths. Using nationwide register-based data on the entire French population provided a large sample size allowing for sufficient power to perform comprehensive and multiple subgroups analyses on the risk of acute arterial events, identify its independent drivers, and thus, strengthen our findings. Additionally, several studies have found the reliability, validity, and accuracy of medical coding in the PMSI database for various diseases to be good.[35-39] In particular, stroke as a primary discharge diagnosis code was associated with a positive predictive value of about 90\%.[40] Regarding ischemic heart disease, the annual incidence rate observed in the general population was in the range of those recently reported in three French regional registries, thus supporting a high validity of the data.[41]

This study also has some limitations that need to be discussed. Cardiovascular risk factors were identified during hospitalisation. Rates of cardiovascular risk factors, including tobacco smoking, may be therefore underestimated,[42] while tobacco smoking may partly account in differences between CD and UC. However, the increased risk of acute arterial events was maintained in CD patients without traditional cardiovascular risk factors compared with the general population. Disease activity was also associated with an increased risk of acute arterial events in both CD and UC, after adjustment of all cardiovascular risk factors recorded. Furthermore, patients with CD had a nearly 2 -fold increase in periods of disease activity compared to patients with UC. Despite the underestimation of tobacco smoking, it may highlight the fact that systemic inflammation is one of the trigger of acute arterial events in patients with IBD and the increased inflammatory burden in patients with CD may account for differences between CD and UC. Furthermore, adjustment for region of residence may to some extent have captured the effect of tobacco smoking, since the prevalence of tobacco smoking in France differs according to the region of residence.[43] 
The definition of active disease was based on IBD-related hospitalisation. Thus, it excludes mild and moderate flares managed in an outpatient setting and treated with regimens such as aminosalicylates. Hence, the risks assessed in our study relate to flares severe enough to require hospitalisation. These flares may be associated with high systemic inflammation and further studies are needed to assess the risk related to mild and moderate flares managed in an outpatient setting. However, surgical procedures were performed in a minority of hospitalisations and we reported consistent findings after exclusion of the postoperative period from the active disease definition, which may exclude the most severe flares. Additionally, active disease was arbitrarily defined as the three months before and after an IBD-related hospitalisation or surgery, while the true duration of risk would vary between individuals. However, we reported consistent findings in sensitivity analyses varying active disease duration.

Data on treatment modalities were not included in the analysis. Therefore, we were not able to use corticosteroids exposure as a surrogate marker of active disease nor to adjust or stratify on the different treatment options. Anti-TNF agents reduce systemic inflammation and could decrease cardiovascular events and related mortality in IBD patients, which has been suggested in patients with rheumatoid arthritis.[5] Further studies are therefore required to assess the impact of treatment on the risk of acute arterial events in IBD patients.

Until now, there has been no validation study of the ICD-10 codes related to IBD in the PMSI. However, a similar cohort from the same inpatient database and including outpatient database has been extensively described and provides evidence on the validity of IBD diagnoses in these databases.[44]

In conclusion, this nationwide population-based cohort study including more than 200,000 patients diagnosed with IBD reported an increased risk of acute arterial events 
in patients with IBD. We determined that the risk was the highest in patients with $C D$ and in young patients compared to the corresponding persons of the general population. We also established a clear link between IBD activity and the risk of acute arterial events. Overall, this study supports the increasing concept that a tight control of inflammation is crucial in IBD patients to avoid IBD-related systemic complications. For arterial diseases and IBD, the impact of therapies, including anti-TNFs, still has to be addressed. 
Funding: The BERENICE project is supported by grants from the French National Agency for Medicines and Health Products Safety (Agence Nationale de Sécurité du Médicament (ANSM)).

Disclosures: The authors disclose the following: Laurent Beaugerie has received lecture fees from Abbott, Abbvie, MSD, Ferring Pharmaceuticals, Janssen, and research support from Abbott, Biocodex and Ferring Pharmaceuticals. Nynne Nyboe Andersen has received lecture fees from MSD and Ferring. Michaël Schwarzinger is an employee of Translational Health Economics Network (THEN), Paris, France that received research grants of Abbvie, Gilead, Merck and co, Novartis, outside and unrelated to the submitted work. Julien Kirchgesner, Fabrice Carrat and Tine Jess disclose no conflicts.

Collaborators of the BERENICE study group are the following: Laurent Beaugerie, Anne-Marie Bouvier, Anne Buisson, Franck Carbonnel, Fabrice Carrat, Jacques Cosnes, Corinne Gower-Rousseau, Julien Kirchgesner, Alain Olympie, Laurent Peyrin-Biroulet, Jean-François Rahier, Frank Ruemmele, Michaël Schwarzinger, Tabassome Simon, Yazdan Yazdanpanah. 
Figure legends:

Figure 1: Study Population Flowchart

Figure 2: Standardised incidence ratios of all acute arterial events according to IBD subtype and age groups

Figure 3: Impact of disease activity (3-month periods before and after IBD-related hospitalisation or surgery) on the risk of acute arterial events according to IBD subtype. Legend: adjusted for age at cohort entry, sex, year of cohort entry, disease activity prior to cohort entry, hypertension, hyperlipidemia, diabetes melittus, obesity, tobacco smoking and alcohol use disorders. 


\section{References}

1 Hansson GK. Inflammation, atherosclerosis, and coronary artery disease. N Engl J Med 2005;352:1685-95.

2 Shankar A, Li J, Nieto FJ, et al. Association between C-reactive protein level and peripheral arterial disease among US adults without cardiovascular disease, diabetes, or hypertension. Am Heart J 2007;154:495-501.

3 Avina-Zubieta JA, Thomas J, Sadatsafavi M, et al. Risk of incident cardiovascular events in patients with rheumatoid arthritis: a meta-analysis of observational studies. Ann Rheum Dis 2012;71:1524-9.

4 Peters MJL, Symmons DPM, McCarey D, et al. EULAR evidence-based recommendations for cardiovascular risk management in patients with rheumatoid arthritis and other forms of inflammatory arthritis. Ann Rheum Dis 2010;69:325-31.

5 Symmons DPM, Gabriel SE. Epidemiology of CVD in rheumatic disease, with a focus on RA and SLE. Nat Rev Rheumatol 2011;7:399-408.

6 Singh S, Singh H, Loftus Jr. EV, et al. Risk of Cerebrovascular Accidents and Ischemic Heart Disease in Patients With Inflammatory Bowel Disease: A Systematic Review and Meta-analysis. Clin Gastroenterol Hepatol 2014;12:382393.e1.

7 Fumery M, Xiaocang C, Dauchet L, et al. Thromboembolic events and cardiovascular mortality in inflammatory bowel diseases: A meta-analysis of observational studies. J Crohns Colitis 2014;8:469-79.

8 Rungoe C, Basit S, Ranthe MF, et al. Risk of ischaemic heart disease in patients with inflammatory bowel disease: a nationwide Danish cohort study. Gut 2013;62:689-94.

9 Bernstein CN, Wajda A, Blanchard JF. The Incidence of Arterial Thromboembolic Diseases in Inflammatory Bowel Disease: A Population-Based Study. Clin Gastroenterol Hepatol 2008;6:41-5.

10 Andersohn F, Waring M, Garbe E. Risk of ischemic stroke in patients with Crohn's disease: a population-based nested case-control study. Inflamm Bowel Dis 2010;16:1387-92.

$11 \mathrm{Ha}$ C, Magowan S, Accortt NA, et al. Risk of Arterial Thrombotic Events in Inflammatory Bowel Disease. Am J Gastroenterol 2009;104:1445-51.

12 Kristensen SL, Ahlehoff O, Lindhardsen J, et al. Disease Activity in Inflammatory Bowel Disease Is Associated with Increased Risk of Myocardial Infarction, Stroke and Cardiovascular Death - A Danish Nationwide Cohort Study. PloS One 2013;8:e56944.

$13 \mathrm{ATIH}$. Agence technique de l'information sur l'hospitalisation. Programme de médicalisation des systèmes d'information (PMSI), présentation. http://www.atih.sante.fr/mco/presentation?secteur=MCO. (accessed 28 Dec 2015) 
14 INSEE. Institut national de la statistique et des études économiques. Répartition des décès selon le lieu du décès [Distribution of deaths according to location]: Institut national de la statistique et des études économiques; 2014. http://insee.fr/fr/themes/detail.asp?reg_id=0\&ref_id=ir-irsocsd20133

IRSOCSD20133_SERIE. (accessed 28 Dec 2015)

15 Collins CE, Rampton DS, Rogers J, et al. Platelet aggregation and neutrophil sequestration in the mesenteric circulation in inflammatory bowel disease. Eur $\mathrm{J}$ Gastroenterol Hepatol 1997;9:1213-7.

16 Hatoum OA, Binion DG. The vasculature and inflammatory bowel disease: contribution to pathogenesis and clinical pathology. Inflamm Bowel Dis 2005;11:304-13.

17 Landesberg G, Beattie WS, Mosseri M, et al. Perioperative Myocardial Infarction. Circulation 2009;119:2936-44.

18 Rein P, Saely $\mathrm{CH}$, Silbernagel $\mathrm{G}$, et al. Systemic inflammation is higher in peripheral artery disease than in stable coronary artery disease. Atherosclerosis 2015;239:299-303.

19 Singh S, Kullo IJ, Pardi DS, et al. Epidemiology, risk factors and management of cardiovascular diseases in IBD. Nat Rev Gastroenterol Hepatol Published Online First: 2 December 2014. doi:10.1038/nrgastro.2014.202

20 Wu G-C, Leng R-X, Lu Q, et al. Subclinical Atherosclerosis in Patients With Inflammatory Bowel Diseases: A Systematic Review and Meta-Analysis. Angiology 2016;::000331971665203. doi:10.1177/0003319716652031

21 Zanoli L, Cannavò M, Rastelli S, et al. Arterial stiffness is increased in patients with inflammatory bowel disease. J Hypertens 2012;30:1775-81.

22 Roifman I, Sun YC, Fedwick JP, et al. Evidence of endothelial dysfunction in patients with inflammatory bowel disease. Clin Gastroenterol Hepatol Off Clin Pract J Am Gastroenterol Assoc 2009;7:175-82.

23 Fagan EA, Dyck RF, Maton PN, et al. Serum levels of C-reactive protein in Crohn's disease and ulcerative colitis. Eur J Clin Invest 1982;12:351-9.

24 Saverymuttu SH, Hodgson HJ, Chadwick VS, et al. Differing acute phase responses in Crohn's disease and ulcerative colitis. Gut 1986;27:809-13.

25 Henriksen M, Jahnsen J, Lygren I, et al. C-reactive protein: a predictive factor and marker of inflammation in inflammatory bowel disease. Results from a prospective population-based study. Gut 2008;57:1518-23.

26 Gross V, Andus T, Caesar I, et al. Evidence for continuous stimulation of interleukin-6 production in Crohn's disease. Gastroenterology 1992;102:514-9.

27 Oussalah A, Guéant J-L, Peyrin-Biroulet L. Meta-analysis: hyperhomocysteinaemia in inflammatory bowel diseases. Aliment Pharmacol Ther 2011;34:1173-84. 
28 Saibeni S, Cattaneo M, Vecchi M, et al. Low Vitamin B6 Plasma Levels, a Risk Factor for Thrombosis, in Inflammatory Bowel Disease: Role of Inflammation and Correlation With Acute Phase Reactants. Am J Gastroenterol 2003;98:112-7.

29 Galluzzo S, Patti G, Dicuonzo G, et al. Association between NOD2/CARD15 polymorphisms and coronary artery disease: a case-control study. Hum Immunol 2011;72:636-40.

30 Hugot JP, Laurent-Puig P, Gower-Rousseau C, et al. Mapping of a susceptibility locus for Crohn's disease on chromosome 16. Nature 1996;379:821-3.

31 Beaugerie L, Seksik P, Nion-Larmurier I, et al. Predictors of Crohn's disease. Gastroenterology 2006;130:650-6.

32 Stowe SP, Redmond SR, Stormont JM, et al. An epidemiologic study of inflammatory bowel disease in Rochester, New York. Hospital incidence. Gastroenterology 1990;98:104-10.

33 Loftus CG, Loftus EV, Harmsen WS, et al. Update on the incidence and prevalence of Crohn's disease and ulcerative colitis in Olmsted County, Minnesota, 1940-2000. Inflamm Bowel Dis 2007;13:254-61.

34 Langholz E, Munkholm P, Davidsen M, et al. Course of ulcerative colitis: analysis of changes in disease activity over years. Gastroenterology 1994;107:3-11.

35 Couris CM, Polazzi S, Olive F, et al. Breast cancer incidence using administrative data: correction with sensitivity and specificity. J Clin Epidemiol 2009;62:660-6.

36 Chantry AA, Deneux-Tharaux C, Cans C, et al. Hospital discharge data can be used for monitoring procedures and intensive care related to severe maternal morbidity. J Clin Epidemiol 2011;64:1014-22.

37 Uhry Z, Remontet L, Colonna M, et al. Cancer incidence estimation at a district level without a national registry: a validation study for 24 cancer sites using French health insurance and registry data. Cancer Epidemiol 2013;37:99-114.

38 Lorgis L, Cottenet J, Molins G, et al. Outcomes After Acute Myocardial Infarction in HIV-Infected Patients Analysis of Data From a French Nationwide Hospital Medical Information Database. Circulation 2013;127:1767-74.

39 Sahli L, Lapeyre-Mestre M, Derumeaux $\mathrm{H}$, et al. Positive predictive values of selected hospital discharge diagnoses to identify infections responsible for hospitalization in the French national hospital database. Pharmacoepidemiol Drug Saf 2016;25:785-9.

40 Giroud M, Hommel M, Benzenine E, et al. Positive Predictive Value of French Hospitalization Discharge Codes for Stroke and Transient Ischemic Attack. Eur Neurol 2015;74:92-9.

41 SPF. Santé Publique France. Les cardiopathies ischémiques. Incidence. http://invs.santepubliquefrance.fr/Dossiers-thematiques/Maladies-chroniques-ettraumatismes/Maladies-cardio-neuro-vasculaires/Les-cardiopathies-ischemiques (accessed 2 Apr2017). 
42 Seksik P, Nion-Larmurier I, Sokol H, et al. Effects of light smoking consumption on the clinical course of Crohn's disease. Inflamm Bowel Dis 2009;15:734-41.

43 Berthier N, Guignard R, Richard J, et al. Regional comparison of tobacco smoking and e-cigarette use in France in 2014. Bull Epidémiol Hebd 2016;30-31:508-14.

44 Kirchgesner J, Lemaitre M, Rudnichi $A$, et al. Therapeutic management of inflammatory bowel disease in real-life practice in the current era of anti-TNF agents: analysis of the French administrative health databases 2009-2014. Aliment Pharmacol Ther 2017;45:37-49. 


\section{Figure 1: Study Population Flowchart}

Patients 15 years or older identified with IBD based on hospital discharge diagnosis between 2008-2013 from the French National Hospital Discharge Database

$$
n=234055
$$

Atrial fibrillation, $n=7453$

Heart failure or cardiomyopathy, $n=3086$

History of an acute arterial event, procedures related to cardiac electronic device, cardiac valve prosthesis, angiography, coronary catheterisation, or coronary artery bypass grafting, $n=13354$ 
Figure 2: Standardised incidence ratios of all acute arterial events according to IBD subtype and age groups

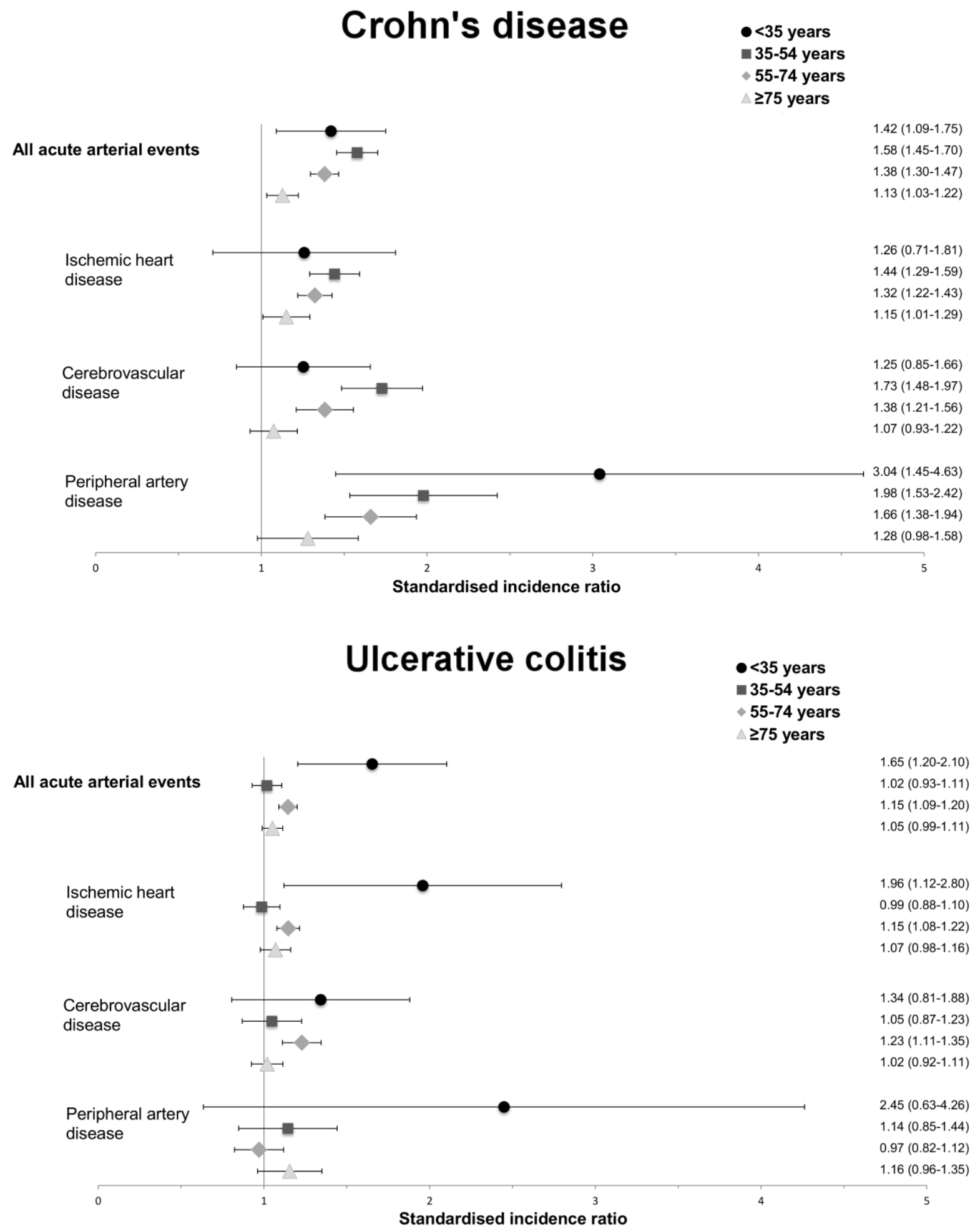


Figure 3: Impact of disease activity (3-month periods before and after IBD-related hospitalisation or surgery) on the risk of acute arterial events according to IBD subtype. Legend: adjusted for age at cohort entry, sex, year of cohort entry, disease activity prior to cohort entry, hypertension, hyperlipidemia, diabetes melittus, obesity, tobacco smoking and alcohol use disorders.

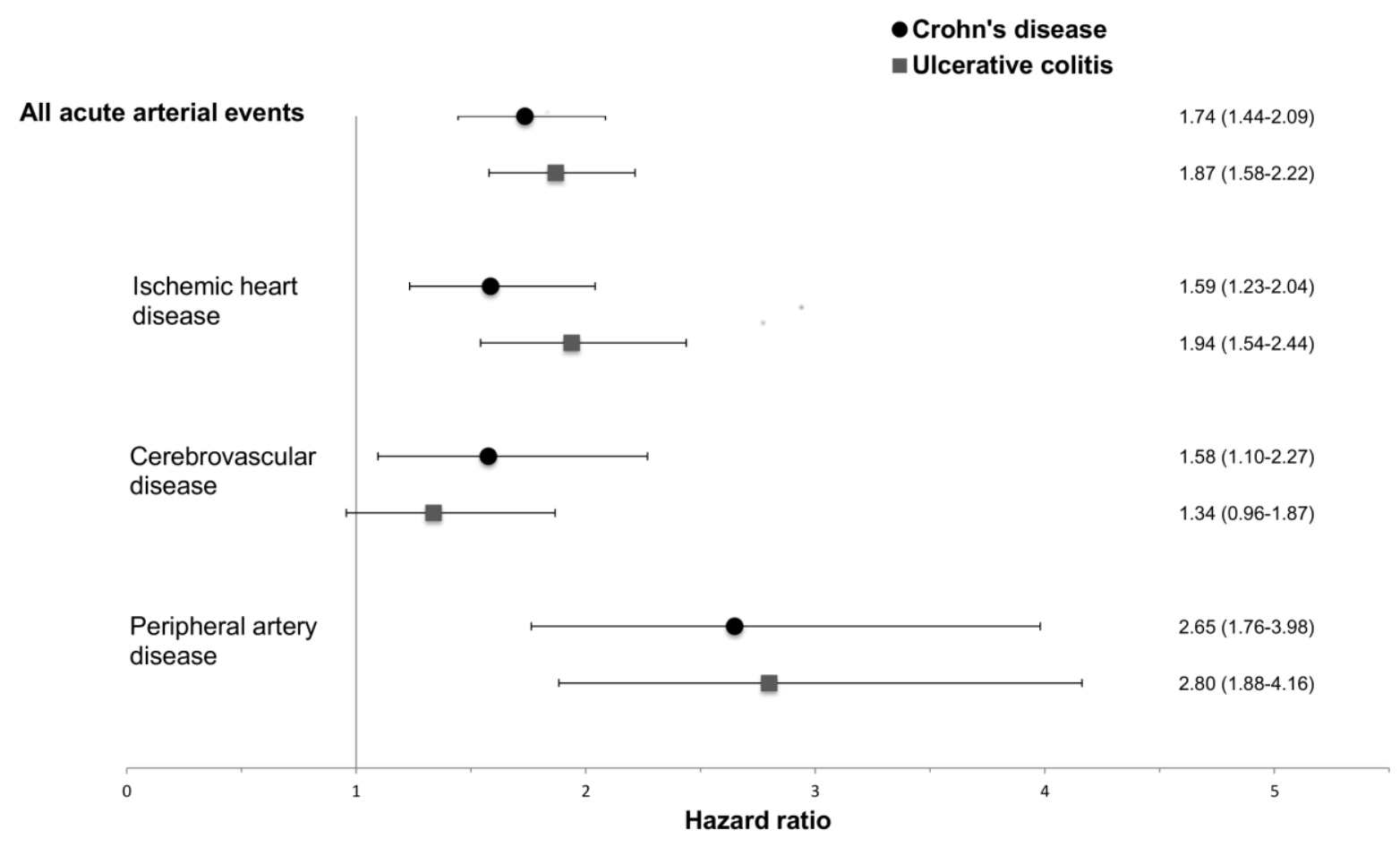




\section{Supplementary material}

Supplementary Table 1. Exclusion criteria and outcomes

Comorbidities prior to cohort entry

ICD-10 codes

French Medical Common

Procedure Coding System

\section{Exclusion criteria}

Ischemic heart disease

Cerebrovascular disease

Peripheral artery disease

Heart Failure

Atrial fibrillation

Cardiomyopathies

\section{Outcomes}

Ischemic heart disease

Myocardial

infarction

Cerebrovascular disease

Stroke

Peripheral artery disease
120-125, T820, T822, T823, T826, T827 Z45.0, Z86.71, Z95 (except $Z 95.8, Z 95.9)$ 160-166, G45, G460-G462, 1670 , I671, I68, I69, Z86.60, Z86.70

150

148

$142-143$

174
Coronary catheterization with arterial dilation; CABG

Cerebral angiography with arterial dilation or embolization Angiography coronary cerebral and mesenteric angiography) with arterial dilation; Peripheral artery bypass

(excluding
120-125

I21-I22

160-164, G45

I60-164 (except I63.6)

174

Coronary catheterization; CABG

Coronary catheterization with arterial dilation; CABG

Cerebral angiography with arterial dilation or embolization

Cerebral angiography with arterial dilation or embolization Angiography (excluding coronary catheterization, cerebral and mesenteric angiography) with arterial dilation; Peripheral artery bypass 
Covariates

ICD-10 codes

French Medical

Common Procedure

Coding System

Cardiovascular risk factors
Hypertension
I10-I13, I15
Hyperlipidemia
E78.0-E78.5
Diabetes mellitus
E10-E14, M14.2 , M14.6, N08.3, H28.0, H36.0, G59.0, G63.2, G73.0, G99.0, 179.2
Obesity
E66
Tobacco smoking
F17, Z71.6, Z72.0, T65.2
F10.1, F10.24, F10.25, F10.26, F10.3, F10.4,
Alcohol use disorders Z50.2, Z71.4, Z72.1, E24.4, E51.1, K70x, G31.2, G62.1, G72.1, 142.6, K29.2, K85.2, K86.0, F10.5, F10.6, F10.7, F10.8, F10.9, $F 10.20, F 10.21, F 10.22, F 10.23$

Digestive endoscopy

Colonoscopy, Upper Gl endoscopy, Capsule Endoscopy

Hospitalisation related to IBD

IBD

Occlusion

$$
\begin{gathered}
\mathrm{K} 50, \mathrm{~K} 51 \\
\mathrm{~K} 56 \\
\mathrm{~K} 63.1, \mathrm{~K} 63.2 \\
\mathrm{~K} 63.0 \\
\mathrm{~K} 60, \mathrm{~K} 61
\end{gathered}
$$

Fistula, perforation

Abscess

Perianal complications

Surgery related to IBD

Colectomy, Intestinal resection, Abscess drainage, Surgical procedure related to anal abscess or fistula 
Supplementary Table 3.Characteristics of patients with acute arterial events among patients with IBD and the French general population

\begin{tabular}{lcccc}
\hline & $\begin{array}{c}\text { Crohn's } \\
\text { disease } \\
\mathrm{n}=2244\end{array}$ & $\begin{array}{c}\text { Ulcerative } \\
\text { colitis } \\
\mathrm{n}=3310\end{array}$ & $\begin{array}{c}\text { IBD Total } \\
\mathrm{N}=5554\end{array}$ & $\begin{array}{c}\text { French general } \\
\text { population } \\
\mathrm{n}=1,555,959\end{array}$ \\
\hline $\begin{array}{cccc}\text { Male sex } \\
\text { Age at event (years) }\end{array}$ & $1208(53.8)$ & $2137(64.6)$ & $3310(59.6)$ & $945,396(60.8)$ \\
Acute arterial event subtype & $61(50-73)$ & $67(57-77)$ & $65(55-75)$ & $68(57-78)$ \\
$\quad$ & & & & \\
Ischemic heart disease & $1253(55.9)$ & $1924(58.1)$ & $3177(57.2)$ & $884,457(56.9)$ \\
$\quad$ Myocardial infraction & $410(18.3)$ & $680(20.5)$ & $1090(19.6)$ & $326,115(21.0)$ \\
Cerebrovascular disease & $694(30.9)$ & $1021(30.9)$ & $1715(30.9)$ & $500,138(32.1)$ \\
$\quad$ Stroke & $626(27.9)$ & $915(27.6)$ & $1541(27.7)$ & $452,544(29.1)$ \\
Peripheral artery disease & $297(13.2)$ & $365(11.0)$ & $662(11.9)$ & $171,364(11.0)$
\end{tabular}

Cardiovascular risk factors recorded

precluding acute arterial events

Hypertension
Hyperlipidemia
Diabetes mellitus
Obesity
Tobacco smoking
Alcohol use disorders

$688(30.7) \quad 1202(36.3) \quad 1890(34.0) \quad 361,622(23.2)$

$244(10.9) \quad 452(13.7) \quad 696(12.5) \quad 129,389(8.3)$

$258(11.5) \quad 509(15.4) \quad 767(13.8) \quad 160,061(10.3)$

$175(7.8) \quad 279(8.4) \quad 454(8.2) \quad 81,370(5.2)$

$279(12.4) \quad 200(6.0) \quad 479(8.6) \quad 67,111(4.3)$

$133(5.9) \quad 159(4.8) \quad 292(5.3) \quad 51,707(3.3)$ 
Supplementary Table 4. Standardised incidence ratios of arterial events according to IBD subtype

Person-years $\begin{gathered}\text { Reported Expected } \\ \text { cases } \\ \text { cases }\end{gathered}$ SIR (CI 95\%) P value

\section{All IBD patients}

All acute arterial events

Ischemic heart disease Myocardial infraction

Cerebrovascular disease

Stroke

Peripheral artery disease

\section{Crohn's disease patients}

All acute arterial events

Ischemic heart disease

Myocardial infraction

Cerebrovascular disease

Stroke

Peripheral artery disease

\section{Ulcerative colitis patients}

All acute arterial events

Ischemic heart disease

Myocardial infraction

Cerebrovascular disease

Stroke

Peripheral artery disease
595,202

$\begin{array}{cccc}5554 & 4679 & 1.19(1.16-1.22) & <.0001 \\ 3177 & 2706 & 1.17(1.13-1.21) & <.0001 \\ 1090 & 1004 & 1.09(1.02-1.15) & <0.01 \\ 1715 & 1446 & 1.19(1.13-1.24) & <.0001 \\ 1541 & 1302 & 1.18(1.12-1.24) & <.0001 \\ 662 & 521 & 1.27(1.17-1.37) & <.0001\end{array}$

287,134

$\begin{array}{cccc}2244 & 1658 & 1.35(1.30-1.41) & <.0001 \\ 1253 & 956 & 1.31(1.24-1.38) & <.0001 \\ 410 & 351 & 1.17(1.05-1.28) & <0.01 \\ 694 & 523 & 1.33(1.23-1.43) & <.0001 \\ 626 & 470 & 1.33(1.23-1.44) & <.0001 \\ 297 & 180 & 1.65(1.46-1.83) & <.0001\end{array}$

308,068

$\begin{array}{cccc}3310 & 3021 & 1.10(1.06-1.13) & <.0001 \\ 1924 & 1750 & 1.10(1.05-1.15) & <.0001 \\ 680 & 653 & 1.04(0.96-1.12) & 0.30 \\ 1021 & 923 & 1.11(1.04-1.17) & <0.01 \\ 915 & 832 & 1.10(1.03-1.17) & <0.01 \\ 365 & 341 & 1.07(0.96-1.18) & 0.21\end{array}$




Person-years $\begin{gathered}\text { Reported } \\ \text { cases }\end{gathered} \quad \begin{gathered}\text { Expected } \\ \text { cases }\end{gathered} \quad \operatorname{SIR}(\mathrm{Cl}$ 95\%) $\quad \mathrm{P}$ value

\section{Crohn's disease patients}

$<35$ years

All acute arterial events

Ischemic heart disease

Myocardial infraction

Cerebrovascular disease

Stroke

Peripheral artery disease

35-54 years

All acute arterial events

Ischemic heart disease

Myocardial infraction

Cerebrovascular disease

Stroke

Peripheral artery disease

55-74 years

All acute arterial events

Ischemic heart disease

Myocardial infraction

Cerebrovascular disease

Stroke

Peripheral artery disease

$\geq 75$ years

All acute arterial events

Ischemic heart disease

Myocardial infraction

Cerebrovascular disease

Stroke

Peripheral artery disease

104,721

$\begin{array}{cccc}71 & 50 & 1.42(1.09-1.75) & 0.01 \\ 20 & 16 & 1.26(0.71-1.81) & 0.36 \\ 6 & 5 & 1.31(0.26-2.35) & 0.56 \\ 37 & 30 & 1.25(0.85-1.66) & 0.22 \\ 30 & 25 & 1.22(0.78-1.66) & 0.32 \\ 14 & 5 & 3.04(1.45-4.63) & 0.01\end{array}$

114,833

$\begin{array}{lccc}621 & 394 & 1.58(1.45-1.70) & <.0001 \\ 353 & 245 & 1.44(1.29-1.59) & <.0001 \\ 127 & 96 & 1.32(1.09-1.55) & <0.01 \\ 192 & 111 & 1.72(1.48-1.97) & <.0001 \\ 174 & 98 & 1.77(1.51-2.03) & <.0001 \\ 76 & 39 & 1.97(1.53-2.42) & <.0001\end{array}$

53,816

$\begin{array}{cccc}1013 & 735 & 1.38(1.29-1.46) & <.0001 \\ 627 & 475 & 1.32(1.22-1.42) & <.0001 \\ 182 & 166 & 1.10(0.94-1.26) & 0.22 \\ 247 & 179 & 1.38(1.21-1.55) & <.0001 \\ 219 & 155 & 1.41(1.22-1.60) & <.0001 \\ 139 & 84 & 1.66(1.38-1.93) & <.0001\end{array}$

13,765

$\begin{array}{cccc}539 & 479 & 1.13(1.03-1.22) & 0.01 \\ 253 & 220 & 1.15(1.01-1.29) & 0.04 \\ 95 & 85 & 1.12(0.89-1.34) & 0.31 \\ 218 & 203 & 1.07(0.93-1.22) & 0.32 \\ 203 & 191 & 1.06(0.91-1.21) & 0.41 \\ 68 & 53 & 1.28(0.97-1.58) & 0.07\end{array}$

\section{Ulcerative colitis patients}

$<35$ years

61,942

All acute arterial events

Ischemic heart disease

Myocardial infraction

Cerebrovascular disease

Stroke

Peripheral artery disease

52

21

7

24

16

7
$31 \quad 1.65(1.20-2.10) \quad<0.01$

$11 \quad 1.96(1.12-2.79) \quad 0.03$

$3 \quad 2.22(0.57-3.86) \quad 0.15$

$18 \quad 1.34(0.80-1.88) \quad 0.21$

$15 \quad 1.08(0.55-1.60) \quad 0.78$

$3 \quad 2.44(0.63-4.26) \quad 0.12$ 
35-54 years

All acute arterial events Ischemic heart disease

Myocardial infraction

Cerebrovascular disease

Stroke

Peripheral artery disease

55-74 years

All acute arterial events

Ischemic heart disease

Myocardial infraction

Cerebrovascular disease

Stroke

Peripheral artery disease

$\geq 75$ years

All acute arterial events

Ischemic heart disease

Myocardial infraction

Cerebrovascular disease

Stroke

Peripheral artery disease
119,822

$\begin{array}{cccc}497 & 489 & 1.02(0.93-1.11) & 0.72 \\ 309 & 314 & 0.98(0.88-1.09) & 0.79 \\ 101 & 127 & 0.79(0.64-0.95) & <0.01 \\ 131 & 125 & 1.05(0.87-1.23) & 0.62 \\ 118 & 111 & 1.06(0.87-1.25) & 0.52 \\ 57 & 50 & 1.14(0.85-1.44) & 0.35\end{array}$

96,526

$\begin{array}{cccc}1660 & 1452 & 1.14(1.09-1.20) & <.0001 \\ 1071 & 936 & 1.14(1.08-1.21) & <.0001 \\ 371 & 333 & 1.11(1.00-1.23) & 0.05 \\ 424 & 346 & 1.23(1.11-1.34) & <.0001 \\ 369 & 299 & 1.23(1.11-1.36) & <.0001 \\ 165 & 170 & 0.97(0.82-1.12) & 0.68\end{array}$

29,778

$\begin{array}{lccc}1101 & 1049 & 1.05(0.99-1.11) & 0.12 \\ 523 & 490 & 1.07(0.98-1.16) & 0.15 \\ 201 & 189 & 1.06(0.92-1.21) & 0.40 \\ 442 & 434 & 1.02(0.92-1.11) & 0.71 \\ 412 & 407 & 1.01(0.92-1.11) & 0.79 \\ 136 & 118 & 1.15(0.96-1.35) & 0.12\end{array}$


Supplementary Table 6. Sensitivity analyses on the hazard ratios for acute arterial events according to IBD subtype.

Disease activity (3-month periods before and after IBDrelated Hospitalisation discharge or surgery)

\section{$\mathrm{HR}(95 \% \mathrm{Cl})$}

Crohn's disease Ulcerative colitis

\section{All acute arterial events}

Main analysis

Age at cohort entry

$$
\begin{aligned}
& 18-54 \text { years } \\
& \geq 55 \text { years }
\end{aligned}
$$

Assessment of cardiovascular risk factors at cohort entry

Exclusion of postoperative period as period of disease activity

Follow-up censored at 30 September 2013

$\begin{array}{ll}2.22(1.67-2.96) & 1.87(1.23-2.84) \\ 1.52(1.20-1.93) & 1.88(1.56-2.26) \\ 1.83(1.52-2.20) & 1.95(1.65-2.31) \\ 1.65(1.36-2.00) & 1.78(1.49-2.13) \\ 1.78(1.47-2.15) & 1.92(1.62-2.29)\end{array}$


Figure Legends :

Supplementary figure 1: Crude incidence rates of acute arterial events in patients with IBD and the general population

Supplementary figure 2: Crude incidence rates of acute arterial events according to age in patients with IBD (A) and the general population (B)

Supplementary figure 3: Standardised incidence ratios of all acute arterial events according to IBD subtype and sex

Supplementary figure 4: Standardised incidence ratios of all acute arterial events according to IBD subtype and number of traditional cardiovascular risk factors (hypertension, hyperlipidemia, diabetes melittus, obesity, tobacco smoking and alcohol use disorders) 


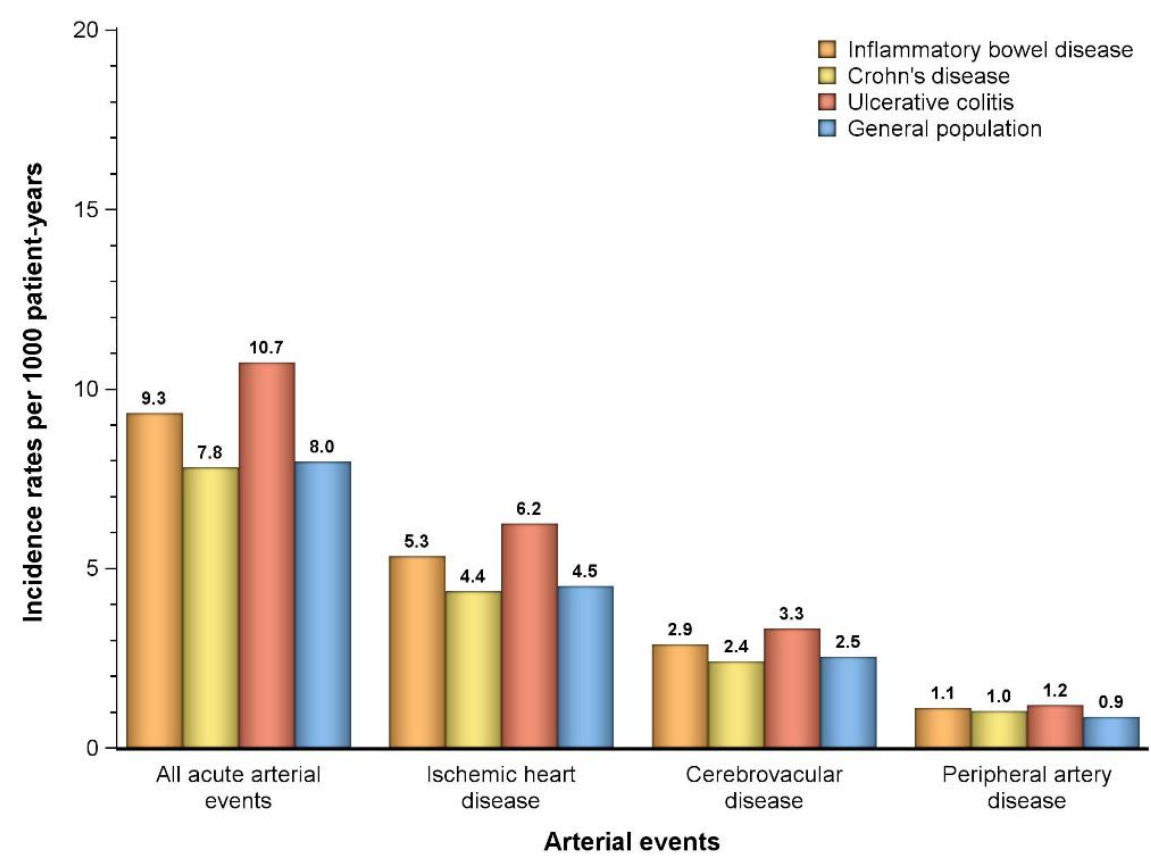

Supplementary figure 1: Crude incidence rates of acute arterial events in patients with IBD and the general population 

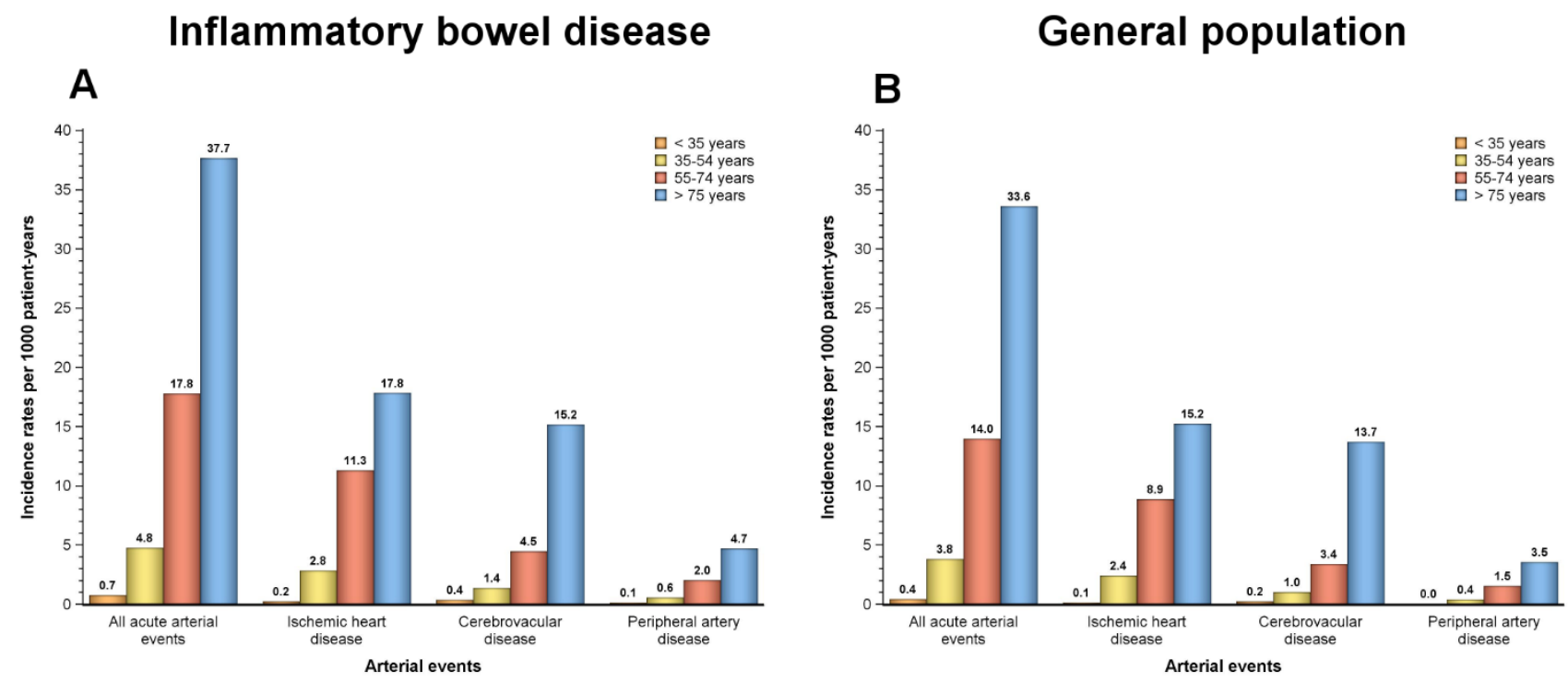

Supplementary figure 2: Crude incidence rates of acute arterial events according to age in patients with IBD $(A)$ and the general population (B) 


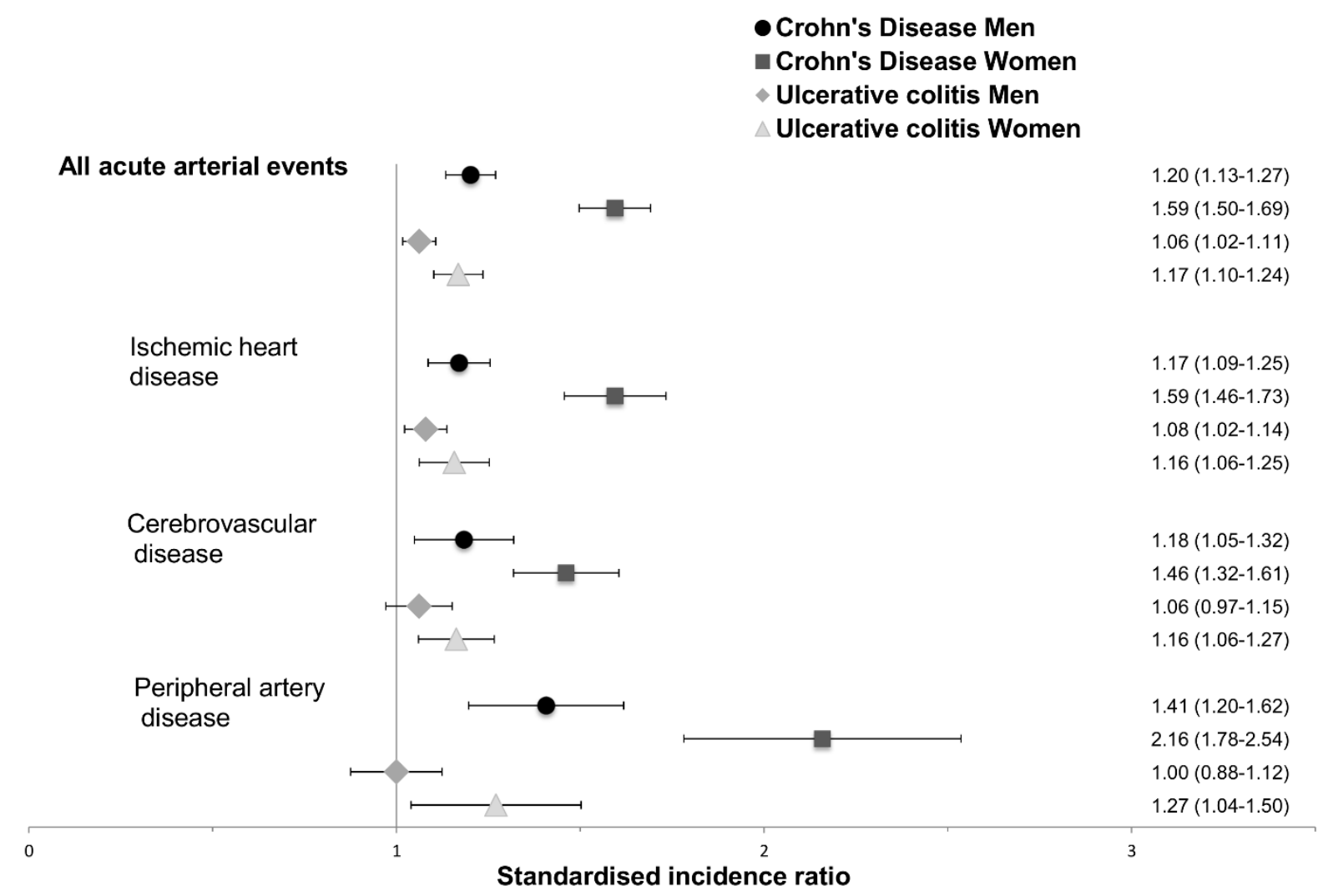

Supplementary figure 3: Standardised incidence ratios of all acute arterial events according to IBD subtype and sex 


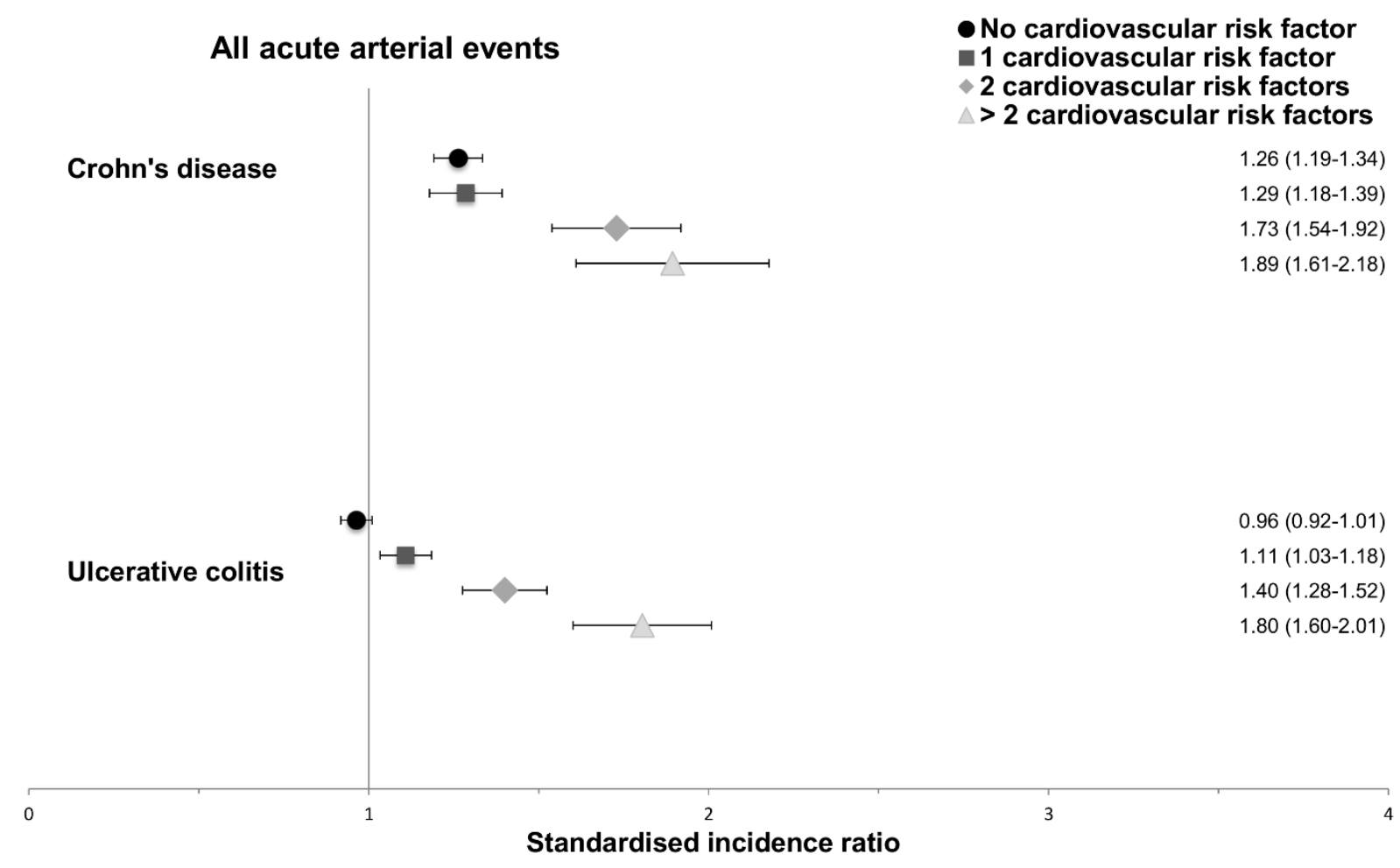

Supplementary figure 4: Standardised incidence ratios of all acute arterial events according to IBD subtype and number of traditional cardiovascular risk factors (hypertension, hyperlipidemia, diabetes melittus, obesity, tobacco smoking and alcohol use disorders) 